\title{
Thrombospondin-2 and SPARC/osteonectin are critical regulators of bone remodeling
}

\author{
Anne M. Delany • Kurt David Hankenson
}

Received: 15 May 2009 / Accepted: 1 October 2009 /Published online: 28 October 2009

(C) The Author(s) 2009. This article is published with open access at Springerlink.com

\begin{abstract}
Thrombospondin-2 (TSP2) and osteonectin/BM40/SPARC are matricellular proteins that are highly expressed by bone cells. Mice deficient in either of these proteins show phenotypic alterations in the skeleton, and these phenotypes are most pronounced under conditions of altered bone remodeling. For example, TSP2-null mice have higher cortical bone volume and are resistant to bone loss associated with ovariectomy, whereas SPARC-null mice have decreased trabecular bone volume and fail to demonstrate an increase in bone mineral density in response to a bone-anabolic parathyroid hormone treatment regimen. In vitro, marrow stromal cell (MSC) osteoprogenitors from TSP2-null mice have increased proliferation but delayed formation of mineralized matrix. Similarly, in cultures of SPARC-null MSCs, osteoblastic differentiation and mineralized matrix formation are decreased. Overall, both TSP2 and SPARC positively influence osteoblastic differentiation. Intriguingly, both of these matricellular proteins appear to impact MSC fate through mechanisms that could involve the Notch signaling system. This review provides an overview of the role of TSP 2 and SPARC in regulating bone structure, function, and remodeling, as determined by both in vitro and in vivo studies.
\end{abstract}

Keywords Bone - Osteoblast - SPARC/osteonectin . Thrombospondin

\author{
A. M. Delany \\ Center for Molecular Medicine, \\ University of Connecticut Health Center, \\ Farmington, CT, USA \\ K. D. Hankenson $(\triangle)$ \\ Department of Animal Biology, School of Veterinary Medicine, \\ University of Pennsylvania, \\ 311 Hill Pavilion, 380 S. University Ave, \\ Philadelphia, PA 19104-4539, USA \\ e-mail:kdhank@vet.upenn.edu
}

$\begin{array}{ll}\text { Abbreviations } \\ \text { CFU-F } & \text { Colony forming unit-fibroblast } \\ \text { ECM } & \text { Extracellular matrix } \\ \text { FTIR } & \text { Fourier-transform infrared } \\ \text { micoCT } & \text { Microcomputed tomography } \\ \text { MSC } & \text { Marrow stromal cell } \\ \text { OI } & \text { Osteogenesis imperfecta } \\ \text { OPG } & \text { Osteoprotegerin } \\ \text { PTH } & \text { Parathyroid hormone } \\ \text { RANKL } & \text { Receptor activator of NFkB ligand } \\ \text { SHG } & \text { Second harmonic generation } \\ \text { SNP } & \text { Single nucleotide polymorphisms } \\ \text { SPARC } & \text { Secreted protein acidic and rich in cystine } \\ \text { TSP2 } & \text { Thrombospondin-2 } \\ \text { UTR } & \text { Untranslated region } \\ \Delta 2 \Delta \text { FosB } & \text { Doubly truncated } \Delta \text { FosB }\end{array}$

\section{Introduction}

Bone structure and formation

Bone is highly-ordered, complex, and composed of multiple tissue types, including mineralized matrix, hematopoietic marrow, and marrow adipocytes. There are two primary types of cells responsible for maintaining bone homeostasis. Osteoblasts are bone-forming cells, and osteoclasts are multi-nucleated bone resorbing cells. Osteoblasts differentiate from progenitors of the mesenchymal lineage, and osteoclasts differentiate from progenitors of the monocyte/ macrophage lineage. Fully mature osteoblasts have one of three fates; they may undergo apoptosis, become quiescent bone-lining cells, or entomb themselves within bone matrix to become osteocytes, which are the cells responsible for 
sensing mechanical strain in the skeleton. After resorbing bone, osteoclasts undergo apoptosis. (Seeman and Delmas 2006).

Developmentally, bone can form by two distinct mechanisms. In endochondral bone formation (ossification), osteoblasts form bone on a cartilaginous template that had previously been synthesized by chondrocytes (growth plate cartilage). For example, most long bones arise from endochondral bone formation, and this mechanism is responsible for longitudinal bone growth. In intramembranous ossification, bone is formed directly by osteoblasts, without a cartilaginous template. During osteoblastic differentiation, mesenchymal progenitors undergo a fairly well-defined differentiation program, characterized by the sequential expression of marker genes such as $\alpha 1$ (I) collagen, bone sialoprotein, and osteocalcin. During this process, cells progress from committed osteoprogentors to fully mature osteoblasts. Early in the differentiation process, osteoblasts begin making osteoid, an extracellular matrix $(\mathrm{ECM})$ rich in collagen and non-collagenous proteins. This ECM is subsequently mineralized by the deposition of a carbonate rich calcium-phosphate apatite within a type I collagen lattice (reviewed by Stein and Lian 1993).

Structurally, bone is composed of compact cortical bone, which surrounds the endocortical compartment. The outer aspect of cortical bone is covered in a cell-rich layer called the periosteum. Located within the endocortical compartment is trabecular bone, also called cancellous bone, which is a network of interconnected bone plates and bars, surrounded by marrow and, in some cases, marrow adipocytes. Trabecular bone tends to be the most metabolically active compartment of the skeleton, undergoing more rapid bone remodeling. In contrast, cortical bone appears more dense and solid, and is remodeled more slowly (Seeman and Delmas 2006).

\section{Bone remodeling}

Bone remodeling, also called bone turnover, is the coupled cycle of bone resorption and bone formation, and it is the only means by which vertebrates can renew bone as adults. Bone is continuously remodeled in response to mechanical and physiological stress. When the rates of bone resorption and formation are balanced, bone mass is maintained. In contrast, when bone resorption out-paces formation, in conditions such as sex steroid deprivation or skeletal unloading, bone loss occurs. It is the number and activity of the bone-forming osteoblasts and the bone-resorbing osteoclasts that determines whether bone remodeling is balanced, or whether bone mass is increased or decreased (Canalis et al. 2007; Seeman and Delmas 2006).
Bone matrix

Bone matrix is a composite of mineral, collagen, noncollagenous proteins, and a small amount of lipid (Robey et al. 2006). The bone matrix provides mechanical support, serves as a calcium and phosphate reservoir, and acts as a local storage depot for cytokines and growth factors. It is also an environment that supports the differentiation and survival of osteoblasts, osteoclasts, marrow stromal cells (MSCs), and cells of the hematopoietic niche. Thus, the composition and organization of the bone matrix can regulate cell behavior. Although non-collagenous proteins comprise only $10-15 \%$ of the total bone protein content, they perform essential functions, such as collagen fibril organization, growth factor binding, regulation of cell-matrix interactions, and regulation of mineralization.

Among the non-collagen bone proteins, the matricellular class of glycoproteins plays a prominent role in bone physiology. Matricellular proteins critical for bone include periostin, tenascin C, SPARC/osteonectin/BM-40, osteopontin, bone sialoprotein, thrombospondin-1 and thrombospondin-2 (reviewed in (Alford and Hankenson 2006). Thrombospondin-2 (TSP2) and SPARC are two well characterized matricellular proteins, and this review will focus on their function in the skeleton, as it relates to bone cell differentiation, control of remodeling, and maintenance of bone mass.

\section{Null mouse skeletal phenotype}

The thrombospondin 2-null mouse

All five thrombospondin (TSP) proteins are expressed in the developing skeleton and by bone cells in vitro (Carron et al. 1999); however, the skeletal phenotypes of mice carrying loss-of-function alleles of the TSP genes are somewhat modest in the absence of remodeling challenges. While this review will focus on TSP2 primarily, skeletal phenotypes have been reported in mice with a global knockout of thrombospondins-1, -3, and -5. TSP1-null mice show a subtle spinal kyphosis (Crawford et al. 1998), and craniofacial dysmorphism (Nishiwaki et al. 2006). TSP3null mice have minor changes in cortical bone and subtle abnormalities in growth-cartilage geometry (Hankenson et al. 2005b). The secondary center of ossification of the femoral head shows accelerated ossification in the TSP3null animals. As expected, more severe skeletal phenotypes are revealed when compound thrombospondin knockout mice are analyzed. For example, craniofacial dysmorphism is more severe in TSP1/TSP2-null mice (Nishiwaki et al. 2006). Further, although single knockouts of TSP1, TSP3, and TSP5 have subtle growth plate abnormalities, com- 
pound knockout of these genes produces severe chondrogenic dysplasia (Posey et al. 2008). These results suggest that a thrombospondin gene 'dosage' may influence skeletal cell phenotype, or that there may be some partial compensation by TSP genes.

The skeletal phenotype in TSP2-null mice was first described in 1998 (Kyriakides et al. 1998a). While TSP2null mice do not display gross abnormalities in skeletal development, 4-month-old TSP2-null mice show an increase in femoral cortical bone thickness by histology, and by peripheral quantitative computed tomography (pqCT). This phenotype is present in both genders, persists at 6months of age, and microcomputed tomography (microCT) high-resolution imaging shows decreases in both periosteal and endocortical perimeters, in addition to an increase in cortical thickness (Fig. 1; (Hankenson et al. 2000). Despite these alterations in cortical bone phenotype, femoral bones from TSP2-null mice have mechanical and functional parameters that are equivalent to those of wild-type animals. Surprisingly, at the ages examined, there were no apparent abnormalities in trabecular bone. Although TSP2null mice show defects in collagen fibrilogenesis (Kyriakides et al. 1998a), bone collagen fibril organization and size
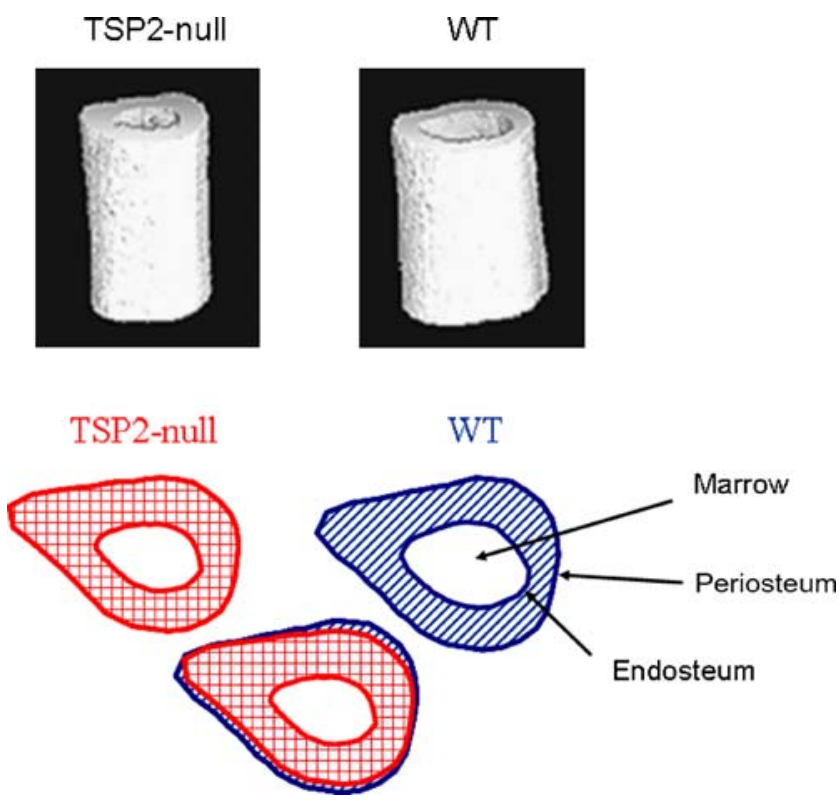

Fig. 1 TSP2-null bones show increased cortical thickness and decreased periosteal and endocortical circumference. MicroCT images adapted from Fig. 1 Hankenson et al. (2000) representing midcortical three-dimensional reconstructions of representative TSP2-null and wild-type femurs. Cartoon diagrams represent the outer fiber length (periosteal radii) and inner fiber length (endocortical radii) in $10^{\circ}$ increments around the centroid plotted as a radar plot (from Fig. 3 Hankenson et al. (2000). Note the increase in cortical thickness and reduction in endocortical and periosteal circumferences in the cortical overlays. Reproduced with permission from Hankenson et al. 2000 appear to be within normal limits. The quality of mineral present in TSP2-null bones has not been thoroughly analyzed; but it is possible that an absence of TSP2 could alter mineral content, a phenomenon observed in bone of other ECM knockout mice, including SPARC (Boskey et al. 2002; Boskey et al. 2003; Ling et al. 2005).

As described previously, alterations in bone mass may arise as a result of alterations in bone formation by osteoblasts, or bone resorption by osteoclasts. TSP2-null mice show an increase in endocortical osteoblast number, and therefore an increase in mineralizing surface and bone formation rate, as determined by calcein double labeling of newly mineralized matrix. This increase in osteoblast number arises secondary to the presence of an increase in osteoblast progenitors, as determined by a colony forming unit-fibroblast (CFU-F) assay. It is interesting to note that in addition to an increase in CFU-Fs, TSP2-null mice also display a subtle increase in total marrow cell number, as determined by counting cell suspensions from entire bone marrow, and by an alteration in megakaryocyte platelet function (Kyriakides et al. 2003). These findings suggest that TSP2 might play an important role in the regulation of the osteoblast lineage, as well as hematopoiesis.

The SPARC-null mouse

SPARC, also commonly called osteonectin, was first described in skeletal tissue, and it is the most abundant non-collagenous extracellular matrix protein in bone (Kuwata et al. 1985; Termine et al. 1984; Robey et al. 2006). Analysis of the skeletal phenotype of SPARC-null mice has provided excellent information on the function of this protein in bone. SPARC-null mice develop profound low-turnover osteopenia (bone loss) that becomes progressively worse with age (Fig. 2). SPARC-null mice also have decreased numbers of osteoblasts and osteoclasts, and a markedly decreased bone-formation rate. Although bone formation rate is decreased nearly $50 \%$ in both trabecular and cortical compartments, it is interesting to note that osteopenia is observed primarily in trabecular bone of SPARC-null mice (Boskey et al. 2003; Delany et al. 2000). SPARC-null mice have decreased trabecular bone volume due to decreased trabecular number. Thus, in the trabecular compartment, bone resorption out paces bone formation, leading to decreased bone mass in these mice. Others have described an increase in extra-skeletal adipose deposits in SPARC-null mice, and increased marrow adiposity in these animals was also reported recently (Mansergh et al. 2007). It is possible that multi-potent stromal cells pursue adipocytic differentiation at the expense of the osteoblastogenesis in these mutant mice (Arthur et al. 2009).

In regard to biomechanical properties, a 3-point bending test shows that cortical bone stiffness peaks in wild-type mice 
Fig. 2 Loss of osteonectin $(\mathrm{ON}) /$ SPARC results in decreased trabecular bone. MicroCT analysis of trabecular bone in vertebrae from 14 week-old SPARC wildtype; $(+/+)$, haploinsufficient (Het: $+/-$ ) and null (-/-) mice. Note differences in bone volume and microarchitecture in mice carrying the osteonectin/SPARCnull allele. Reproduced with permission from Machado do Reis et al. 2008
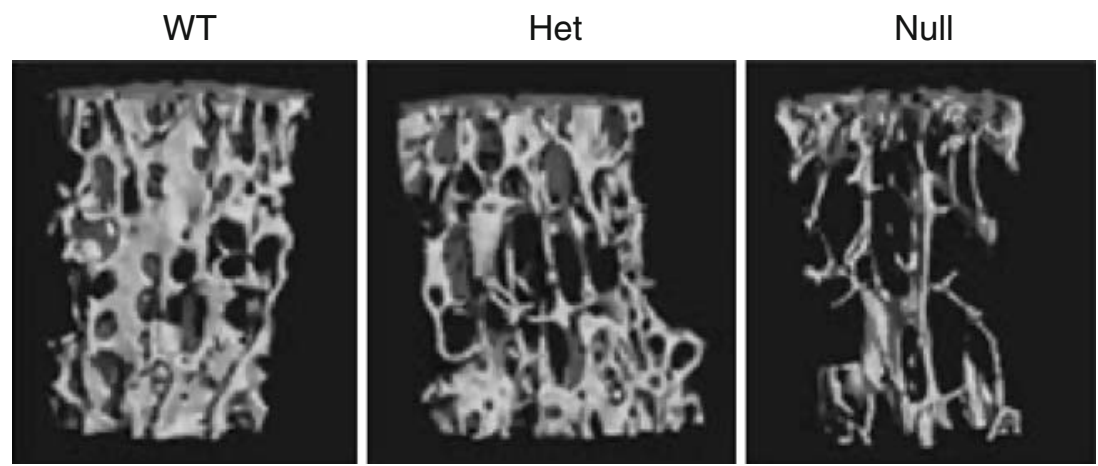

at 17 weeks of age. In contrast, cortical stiffness remains relatively constant in SPARC-null mice, such that stiffness of femurs from SPARC-null mice is similar at 11, 17, and 36 weeks of age (Delany et al. 2000). Further, analysis of bone from SPARC-null mice, using Fourier-transform infrared (FTIR) microscopy, shows decreased mineral to matrix ratio, decreased crystalinity, and increased collagen maturity compared with wild-type bone (Boskey et al. 2003) (Fig. 3). These data confirm decreased bone formation and decreased bone remodeling in the mutant mice.

Second harmonic generation (SHG) imaging allows visualization of collagen matrix secondary structure (Nadiarnykh et al. 2007). Application of this technique to bone sections from wild-type and SPARC-null mice demonstrated appreciable differences in the structure of both cortical and trabecular bone (Fig. 4). Brighter SHG signal is associated with increased amounts of collagen and/or a greater amount of collagen organization. Bone from SPARC-null mice generated a more diffuse SHG signal and appeared less structured. Significant differences in the expression of type I collagen alpha 1 mRNA were not detected in RNA isolated from whole bone or from cultured osteoblasts, and the collagen content of matrix synthesized by wild-type and SPARC-null osteoblasts in vitro was fairly similar. Together, these data suggest that wild-type and SPARC-null cells may have equivalent levels of collagen synthesis, and that collagen fibrils are less organized in SPARC-null bone.

Finally, in vivo studies demonstrate that SPARC gene dosage has a dramatic effect on trabecular bone volume (Fig. 2). MicroCT analysis shows that SPARC haplo-
Fig. 3 Fourier-transform infrared imaging of cortical bone from tibia of 11 week old wildtype and SPARC-null mice. Mineral to matrix ratio, mineral crystallinity (1030/1020 ratios), and collagen maturity are shown. The numerical scales represent the range of intensity ratios for each parameter. Background (PMMA embedding medium) was assigned a value of zero. Reproduced with permission from Boskey et al. 2003

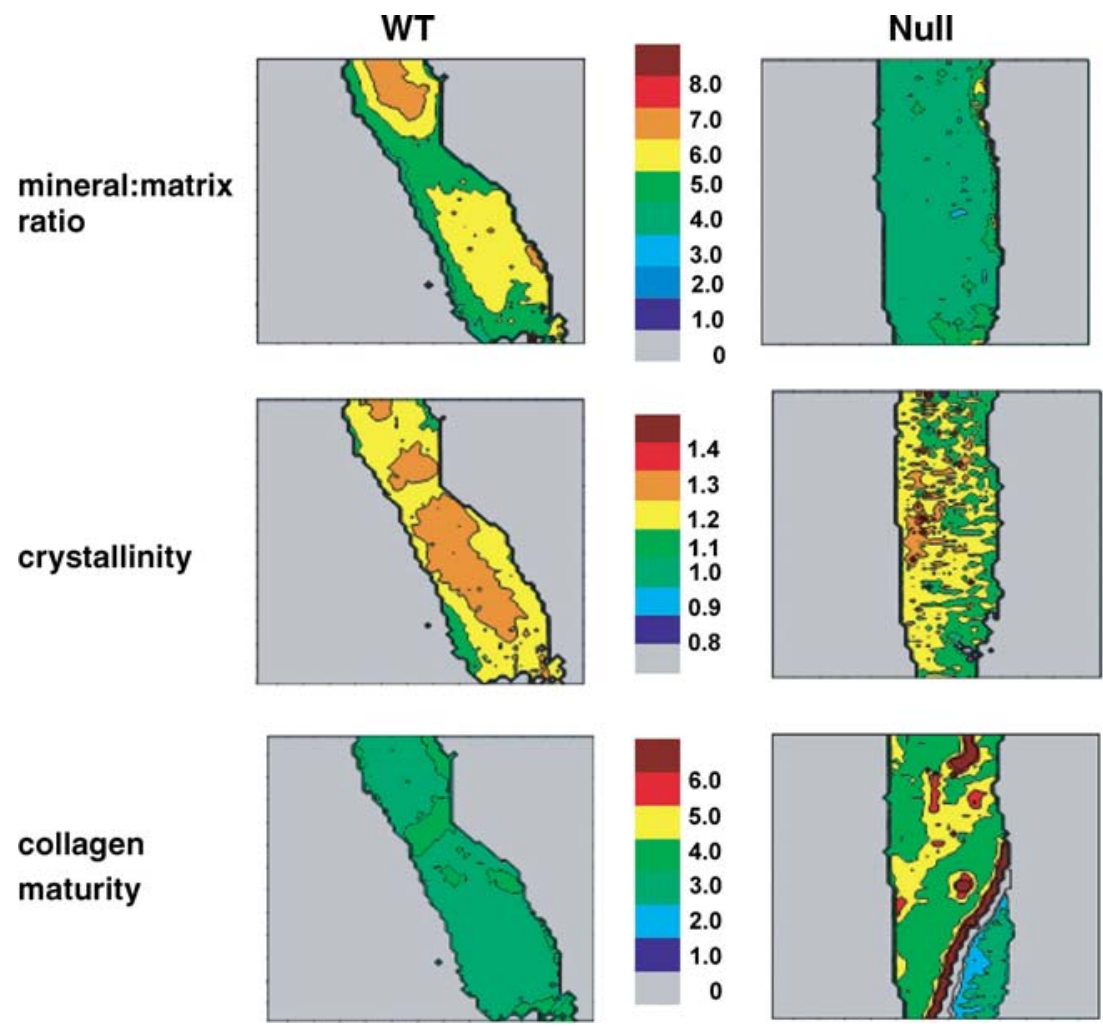


Fig. 4 Second harmonic generation (SHG) imaging of cortical (top) and trabecular (bottom) bone from tibia of 11 week old wild type and SPARC-null mice. Note brighter SHG signal, associated with increased amounts of collagen and/or a greater amount of collagen organization, in wild-type compared with SPARC-null bone

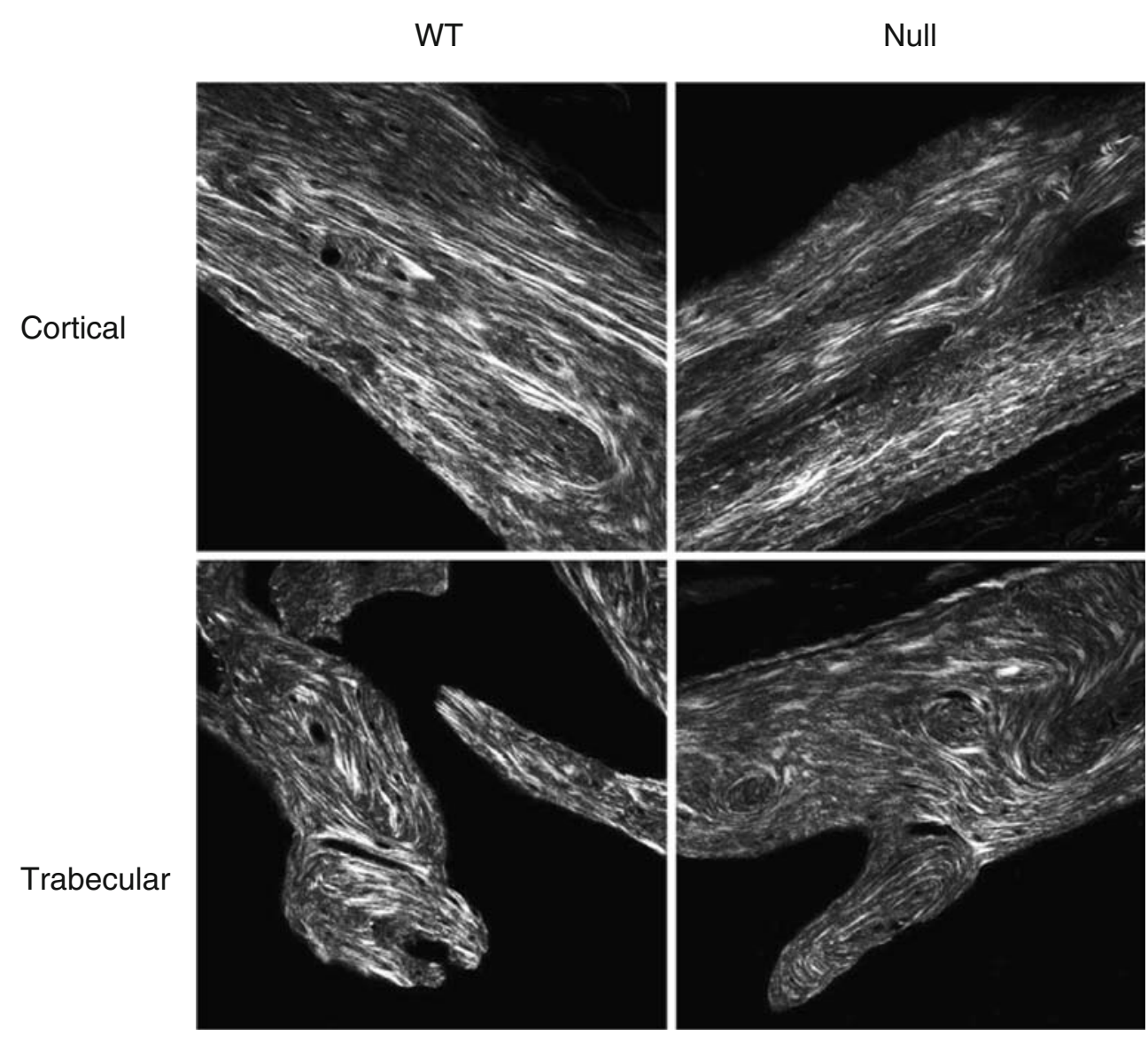

insufficient mice $(+/-)$ have significantly decreased trabecular bone volume, with profound effects on microarchitecture (Machado do Reis et al. 2008). This finding is important because haplotypes, consisting of 3 single nucleotide polymorphisms (SNPs) in the 3' untranslated region (UTR) of the SPARC gene, were associated with bone density in a cohort of Caucasian men with idiopathic osteoporosis (Delany et al. 2008). The 3' UTR has the potential to regulate gene expression through modulation of mRNA stability, targeting and translation. These SNPs within the SPARC 3' UTR could regulate SPARC synthesis, suggesting that SPARC levels may vary among individuals.

Indeed, there is decreased synthesis of SPARC in osteoblasts from patients with osteogenesis imperfecta (OI) and in several animal models of OI (Fedarko et al. 1992; Fisher et al. 1987; Muriel et al. 1991). It is not known whether decreased levels of SPARC are a result of the abnormal bone matrix associated with OI or whether the decreased SPARC levels contribute to the disease phenotype. The association of SPARC 3' UTR haplotypes with bone mass in a subset of men with idiopathic osteoporosis, in addition to the phenotype of SPARC-null and haploinsufficient mice, supports the idea that appropriate levels of SPARC play a critical role in regulating bone remodeling and maintaining bone mass.

\section{In vitro mechanistic studies}

Thrombospondin-2

Thrombospondin proteins are well-recognized regulators of both apoptosis and proliferation (Armstrong et al. 1998; Lawler 2000; Streit et al. 1999). In addition to TSP2-null mice having more CFU-Fs, the size of the colonies formed by the CFU-Fs is increased (Hankenson et al. 2000). In part, CFU-F size reflects post-plating proliferation and survival of clonally derived cells. TSP2-null MSC, grown at 1st passage, show increased proliferation, without any apparent changes in apoptosis (Hankenson and Bornstein 2002). Indeed, cultures of TSP2-null MSCs have an increase in the number of cells in $\mathrm{S}$ phase of the cell cycle, as determined by propidium iodide staining and flow cytometry. Add-back of purified recombinant TSP2 decreases proliferation in a dose-dependent manner, without induction of apoptosis, and temporarily arrests cells in the G0/G1 phase of the cell cycle. Upon removal of TSP2 from cultures of TSP2-null cells, the cells were able to reenter normal cycling. Importantly, the phenotypic profiling of MSC populations from wild-type and TSP2-null mice by flow cytometry is similar. Although murine marrow-derived MSC are frequently contaminated with monocyte lineage 
cells, TSP2-null and wild-type MSC preparations show a similar percentage of cells expressing Mac1 surface antigen, as well as the MSC markers Thy1, CD105, Sca1, and CD44 (Hankenson and Bornstein 2002).

Growth of murine osteoblasts or MSC in medium containing ascorbic acid and $\beta$-glycerol phosphate induces a wellcharacterized osteoblastic differentiation program, ultimately resulting in the formation of mineralized nodules with characteristics of woven bone (Malaval et al. 1999). Passaged cultures of TSP2-null MSCs show a delay in mineralization; however, they ultimately achieve an end state of mineralization similar to that of wild-type cells. This delay in mineralization is accompanied by a delay in the expression of osteoblast-associated genes, such as osteocalcin and collagen type I (Hankenson and Bornstein 2002). It appears that this delay in mineralization is the result of the absence of TSP2 in culture, because the knockdown of TSP2, using siRNA in the osteoblastic cell line MC3T3E1, results in reduced mineralization (Alford et al. 2009). Interestingly, in this highly proliferative pre-osteoblast cell-line, TSP2 knockdown does not affect proliferation, thus suggesting that effects of TSP2 on precursor proliferation and differentiation are mechanistically independent.

One possible molecular mechanism that could link the effects of TSP2 on both proliferation and osteoblastogenesis is the recently reported regulation of Notch signaling by TSP2. Meng et al. demonstrated that TSP2 could bind the receptor Notch3 and its ligand Jagged1 (Meng et al. 2009). Notch signaling is believed to maintain cells in an undifferentiated state, increasing progenitor number, and inhibiting osteoblastic differentiation (Hilton et al. 2008). It is interesting to speculate that TSP2 could affect MSC dynamics, including osteoblastogenesis, at least in part, by inhibiting Notch signaling.

\section{SPARC}

In vitro study of osteoblasts and MSCs from SPARC-null mice has also provided data helpful for understanding their skeletal phenotype. For example, in vitro studies show that MSC preparations from SPARC-null mice have 10-20\% fewer osteoblastic precursors compared with marrow from wild type mice. Wild type and SPARC-null cells do not display significant differences in DNA synthesis, however our studies were the first to demonstrate that SPARC-null cells are more sensitive to cell death induced by serum deprivation. This cell-survival defect could be rescued in osteoblasts by retroviral gene transfer of a construct constitutively expressing SPARC, but not by the addition of recombinant SPARC to the culture medium (Delany et al. 2003). These data suggest that one mechanism by which SPARC supports normal bone remodeling is by enhancing the survival of osteoblasts and stromal cells.
When SPARC-null osteoblasts are subjected to an in vitro differentiation protocol similar to that described previously (Malaval et al. 1999), their expression of early and mid-differentiation markers, such as osteopontin and bone sialoprotein, is similar to that of wild type cells. However, the SPARC-null cells express significantly less osteocalcin mRNA, a marker of fully mature osteoblasts, and display decreased formation of mineralized nodules (Delany et al. 2003). These data suggest that SPARC-null osteoblasts do not fully mature.

Osteoblasts and adipocytes differentiate from a common mesenchymal precursor (Arthur et al. 2009). When SPARCnull osteoblastic cells were grown under conditions favoring osteoblastogenesis, we consistently observed a higher proportion of cells displaying adipocytic differentiation, as evidenced by the presence of Oil Red-O-positive lipid droplets inside the cells. Compared with wild type cells, SPARC-null osteoblast cultures also have a higher expression of adipsin mRNA, a marker for mature adipocytes. In addition, SPARC-null osteoblasts have decreased expression of $\Delta 2 \Delta \mathrm{FosB}$ (doubly truncated $\Delta \mathrm{FosB}$ ), an N-terminally truncated version of the $\mathrm{C}$-terminally truncated splice variant of FosB (Delany et al. 2003). Increased levels of $\Delta 2 \Delta \mathrm{FosB}$ enhance osteoblastic differentiation and repress adipogenesis (Kveiborg et al. 2004; Sabatakos et al. 2008). Further, SPARC-null osteoblasts have increased expression of the cell fate regulator, Notch1, and increased Notch signaling (Kessler and Delany 2007). Notch signaling retains cells in a less differentiated state and suppresses osteoblast differentiation (Hilton et al. 2008). Our data suggest that SPARC-null osteoblasts are less committed to osteoblastic differentiation and are able to pursue adipogenic differentiation, given the appropriate signals.

\section{In vivo remodeling challenges}

\section{Thrombospondin-2}

Considering the relatively subtle bone phenotype of TSP2null mice and the necessity of challenging mice to unmask physiologically relevant phenotypes, a variety of approaches have been used to manipulate the phenotype of TSP2-null mice, including ovariectomy, skeletal loading and fracture (Hankenson et al. 2005a, 2006; Taylor et al. 2009). In wildtype mice, ovariectomy results in a loss of endocortical bone and an expansion of the periosteal perimeter, due to increases in endocortical osteoclastogenesis and periosteal osteoblastogenesis. However, ovariectomized TSP2-null mice maintain their normal bone geometry, relative to wild-type mice (Hankenson et al. 2005a). This alteration in remodeling in TSP2-null mice occurs for several reasons. First, ovariectomized TSP2-null mice experience an amplified activation of 
the stromal compartment, and a four-fold increase in MSC number. Second, whereas ovariectomy-induced osteoclast resorption does occur at the endocortical surface, overall resorption, as measured by release of the collagen degradation product NTx, is reduced in mutant mice compared with the wild-type. Finally, there is a reduction in periosteal expansion. Whether this reduction is a direct effect of the TSP2 deficiency in periosteal osteoblasts, or reflects a lack of a biomechanical need for enhanced periosteum, has not been established.

The concept of altered periosteal bone formation in TSP2null mice is further supported by experiments evaluating the effects of mechanical loading on bone formation. Mechanical loading of the tibia has a well-recognized anabolic effect on periosteal bone formation (Gross et al. 2002). When TSP2null mice were challenged daily with tibial loading, osteoblast activation, demonstrated by the incorporation of calcein into single labeled-surfaces, was observed. However, there was an absence of significant periosteal double labeledsurface, indicating a lack of osteoblast mineral apposition. Interestingly, there was an increase in endocortical doublelabeled surface, indicating increased bone formation rate on this surface in the TSP2-null, and this was not observed with wild-type mice. This reversal in surface responsiveness is unexpected and supports the concept that there is an increase in MSC osteoblast progenitors in the endocortical compartment, and that perhaps, similar to observations with ovariectomy, periosteal osteoblast function might be altered in TSP2-null mice.

Since TSP2 plays a key role in cutaneous wound healing (Kyriakides et al. 1998b), TSP2-null mice were challenged using a tibial fracture bone regeneration model. Bone heals by both endochondral and intramembranous mechanisms, and TSP2 is highly expressed in the early mesenchymal phase of fracture healing (Taylor et al. 2009). TSP2-null mice showed an altered pattern of healing, with a reduction in endochondral bone formation and an increase in intramembranous bone formation (Taylor et al. 2009) (Fig. 5). Further investigation demonstrated that relatively early post-fracture, at day 5, TSP2-null MSC have increased expression of osteoblast-associated genes, but a decrease in expression of chondrogenic genes. These findings suggest that the presence of TSP2 may influence the course of mesenchymal callus progenitors, away from chondrogenic pathways and toward osteogenesis. Associated with this phenotype, the fracture callus in TSP2-null mice displayed an increase in vascularization and a reduction in hypoxia markers. Thus, the influence of TSP2 on bone regeneration may occur, in part, through its well-recognized role in regulating angiogenesis.

\section{SPARC}

Parathyroid hormone (PTH) is a potent stimulator of bone remodeling. When administered in an intermittent manner, bone formation outpaces bone resorption, resulting in a net increase in bone mass. Currently, intermittent administration of PTH peptide 1-34 is the only anabolic therapy available for patients with severe osteoporosis (Canalis et al. 2007). When wild-type and SPARC-null mice are treated with a bone anabolic PTH regimen, the wild-type mice display a significant increase in whole body bone mineral density, whereas the SPARC-null mice do not. Although wild-type and SPARC-null mice demonstrate a similar osteoblastic response to $\mathrm{PTH}$, bone resorption parameters are accentuated in PTH-treated SPARC-null mice. Compared with wild-type mice, the fold increase in eroded surface in response to PTH treatment is higher in SPARC-null animals, as is the fold increase in osteoclast number (Machado do Reis et al. 2008).

PTH treatment of bone marrow cells in vitro results in the formation of multinucleated osteoclasts, due primarily to the up-regulation of RANKL (receptor activator of NFkB ligand) and the down-regulation of the RANKL decoy receptor, OPG (osteoprotegerin) (Lee and Lorenzo 1999). Culture of SPARC-null bone marrow cells with PTH $(10 \mathrm{nM})$ results in the formation of 10-fold more osteoclasts compared with wild-type marrow cultures. Thus, PTH has a
Fig. 5 TSP2-null mice have a reduction in cartilage formation during fracture healing. Whole tibias, 10 days post-fracture, were sectioned in paraffin and stained with Safranin-O to detect cartilage (red color). a TSP2-null fractures contain much less cartilage at day 10 than b wild-type fractures. Reproduced with permission from Taylor et al. 2009 a Wild-type

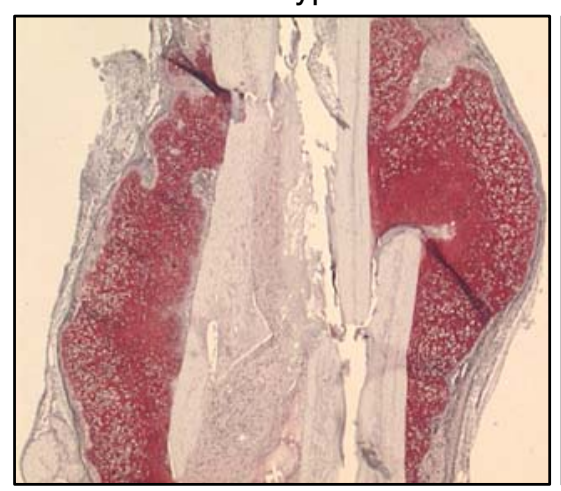

b

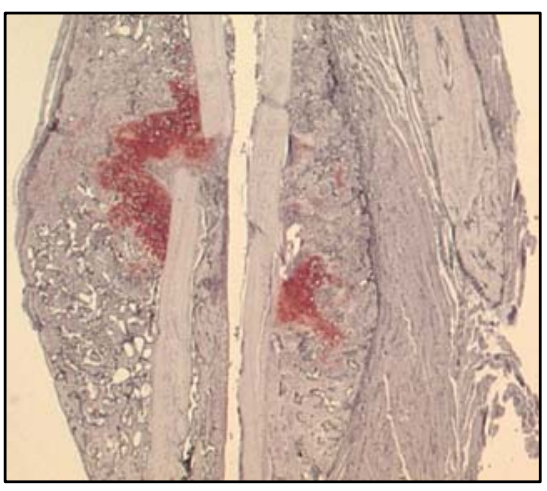


greater effect on osteoclastogenesis in SPARC-null cells in vivo and in vitro. Although SPARC-null marrow cells are not more sensitive to RANKL, PTH-treated SPARC-null marrow cells did express more RANKL mRNA than PTH treated wild type cells. However, the overall ratio of RANKL to OPG mRNA in PTH-treated SPARC-null cultures is actually lower than that found in corresponding wild-types, owing to an attenuated decrease in OPG mRNA in the mutant cells (Machado do Reis et al. 2008). Thus, whereas increased expression of RANKL in response to PTH treatment may contribute to the increased osteoclast formation and activity in SPARC-null mice, it is also likely that other mechanisms are involved.

SPARC is expressed by some myelo-macrophage cell lines and by lymphoma cells (Oritani and Kincade 1996). However, expression of SPARC by osteoclasts has not been reported. Therefore, the mechanisms by which SPARC limits osteoclast formation may involve the direct interaction of extracellular SPARC with osteoclasts or osteoclast precursors, and/or the effect of SPARC on the phenotype of the immune cells, marrow stromal cells, and osteoblasts supporting osteoclast development (Machado do Reis et al. 2008).

\section{Regulation of thrombospondin-2 and SPARC in skeletal cells}

\section{TSP2}

The TSP2 promoter has been well-characterized at the genomic level (Adolph et al. 1997), but relatively little is known about mechanisms regulating TSP2 expression. TSP2 is up-regulated in quiescent cells by growth factor stimulation (Bornstein et al. 1991; Laherty et al. 1992) and TSP2 transcript stability is down-regulated by myb (Bein et al. 1998). TSP2 is highly expressed in the developing skeleton in both intramembranous and endochondral bone formation sites (Iruela-Arispe et al. 1993; Kyriakides et al. 1998c). TSP2 is not expressed by hematpoietic lineage cells, rather it is produced by osteoblast lineage cells (Hankenson and Bornstein 2002). Nishiwaka et al showed that TSP2 expression is regulated by the AP1 transcription factor Fra1 in bone cells (Nishiwaki et al. 2006). In adult bone, TSP2 expression levels are relatively low, but increase remarkably with bone injury (Taylor et al. 2009). This is consistent with other studies demonstrating an increase in TSP2 during tissue injury in skin (Kyriakides et al. 1999), muscle (Krady et al. 2008), and heart (Schroen et al. 2004). These findings may reflect a role for TSP2 in regulation of progenitor pool populations.

In vitro, TSP2 gene expression and protein secretion are up-regulated during osteoblast differentiation (Alford et al. 2009) and TSP2 decreases with adipogenesis (Shitaye et al.
2005). TSP2 is down-regulated during adipogenesis via a cAMP-mediated signaling mechanism. However, minimal promoters that reflect endogenous gene regulation have not been identified.

\section{SPARC}

It is well established that a purine-rich element in the proximal SPARC promoter, highly conserved among the mouse, human and bovine genes, is necessary for maximal promoter activity in osteoblasts (Hafner et al. 1994; Dominguez et al. 1991). This proximal GGA-rich region binds SP1/3 in chick embryo fibroblasts and mediates the down-regulation of SPARC by v-Jun transformation (Chamboredon et al. 2003). There is evidence for transcriptional induction of the SPARC gene by transforming growth factor beta-1, glucocorticoids, and retinoic acid, although specific regulatory motifs have not been identified (Ng et al. 1989; Wrana et al. 1988). Most recently, regulation of SPARC transcription by an element in the third intron, and by promoter hypermethylation have been described in cancer cells (Li et al. 2007; Yang et al. 2007). In contrast to data on transcription, fibroblast growth factor (FGF) 2 is the only growth factor or hormone currently known to regulate SPARC RNA stability in osteoblasts (Delany and Canalis 1998).

In the course of examining the regulation of SPARC expression during the differentiation of osteoblastic cells in vitro, we and others observed that SPARC mRNA levels remain relatively constant in both mouse and human cells (Fig. 6) (Dieudonn et al. 1999; Frank et al. 2002; Kapinas et al. 2009). Western blot analysis of the cell layer from cultured mouse calvarial osteoblasts shows accumulation of SPARC during osteoblastic differentiation, likely in association with collagen matrix. However, analysis of 24 hourconditioned medium shows that secreted SPARC levels are highest early in differentiation, but decrease as the cells acquire more osteoblastic characteristics. This expression pattern seems appropriate because SPARC regulates collagen fibril assembly, and matrix is abundantly deposited in the earlier stages of differentiating cultures (Barker et al. 2005; Lian and Stein 1992; Stein and Lian 1993). The discrepancy between levels of SPARC mRNA and protein later in osteoblast differentiation suggest regulation at the level of translation. Importantly, the expression of a set of microRNAs (miRNAs) known to inhibit SPARC RNA translation, miR-29a and -29c, are coordinately increased as SPARC protein levels are decreased (Fig. 6, Kapinas et al. 2009).

Generally, miRNAs are negative regulators of gene expression that function by interacting with the 3' UTR of target mRNAs and directing suppression of translation and/ or transcript destabilization (Bartel and Chen 2004; Jing et 


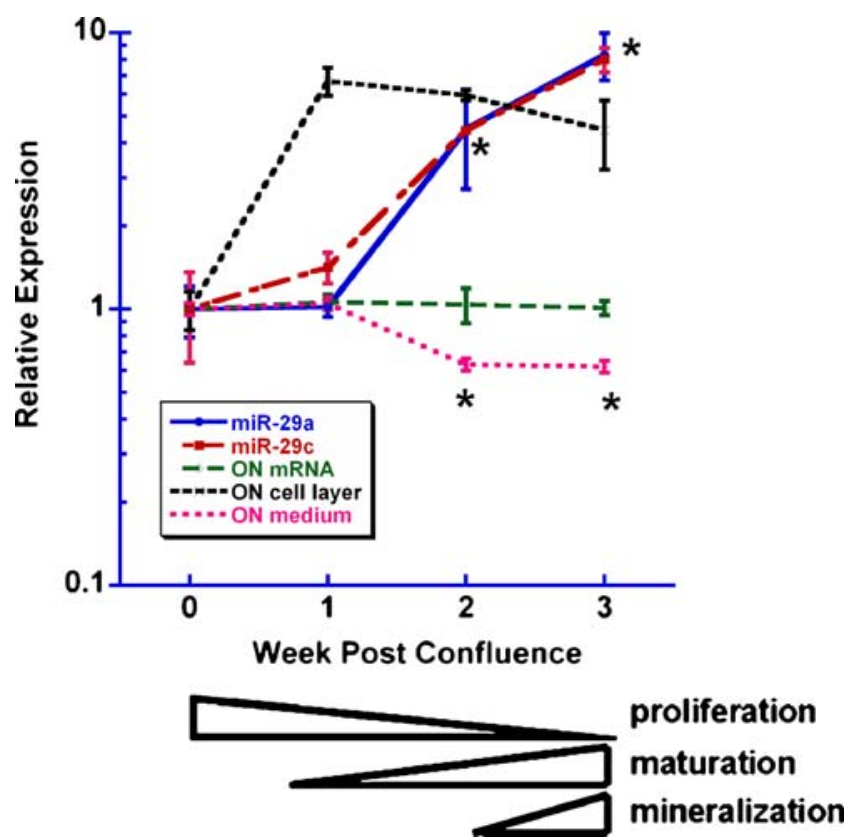

Fig. 6 Reciprocal regulation of miR-29 and SPARC during osteoblast differentiation in vitro. Fold change in expression of osteonectin (ON)/ SPARC mRNA (green), relative quantity of miR-29a (blue) and $-29 \mathrm{c}$ (red), osteonectin (ON)/SPARC protein in the cell layer (black) and $24 \mathrm{~h}$ conditioned medium (pink) in primary mouse calvarial osteoblasts cultured for up to 3 weeks post-confluence under osteoblast differentiation conditions. Expression levels at confluence (week 0) were used as a base line. Note that curves for miR-29a and $-29 \mathrm{c}$ are super-imposable. mean $\pm \mathrm{SEM} *=$ significantly different from week $0, p \leq 0.01$. A general model illustrating the phases of osteoblastic phenotype development (cell proliferation, extracellular matrix maturation, and mineralization) was modified from Stein and Lian 1993). Reproduced with permission from Kapinas et al. 2009

al. 2005; Lewis et al. 2003). Importantly, miRNAs provide an additional level of regulation that can be rapidly and reversibly deployed. Such post-transcriptional regulation may also be more efficient, as RNAs of genes targeted by miRNAs could be more stable (Bartel and Chen 2004). This scenario fits well with what is known about SPARC. The SPARC transcript has a long half-life, $>24 \mathrm{~h}$ under conditions of transcription arrest (Delany and Canalis 1998). This finding implies that it would be difficult to silence SPARC expression rapidly through transcriptional mechanisms.

The 3 potential binding sites for the miR-29 family of miRNAs are clustered within the highly conserved proximal portion of the SPARC 3' UTR, and clustered miRNA binding sites mediate the most efficient repression of gene expression (Bartel 2004). Our data suggest that the miR-29 binding sites play a dominant role in the posttranscriptional regulation of SPARC in osteoblasts. It is interesting to note that the region containing the miR-29 binding sites does not contain any SNPs in humans or mice. It is possible that the regulation mediated by the miR-29 binding sites is critical for appropriate gene expression in multiple tissues, and alterations in these elements could be evolutionarily disadvantageous.

\section{Conclusions and future directions}

In skeletal progenitors, TSP2 and SPARC may regulate osteoblastic lineage progression at multiple levels (Fig. 7); however, their effects seem to be highly contextual. TSP2 appears to play a role in decreasing proliferation, while SPARC may have a positive role in progenitor cell expansion. On the other hand, both TSP2 and SPARC positively influence osteoblast differentiation, while limiting adipogenesis.

While the effects of TSP2 on proliferation and differentiation of MSC appear to be uncoupled, the molecular mechanisms by which TSP2 regulates the osteoblast lineage are still not entirely clear. Recent work focused on Notch signaling has shown that TSP2-null MSC have an increase in Notch signaling (Shitaye et al. 2009), which could, in part, account for the increased cell number and reduced osteoblast differentiation of TSP2-null MSC. It is also possible that TSP2 could have a direct role in the process of mineralization. TSP2 is enriched in matrix vesicles involved in mineralization (Xiao et al. 2007), and

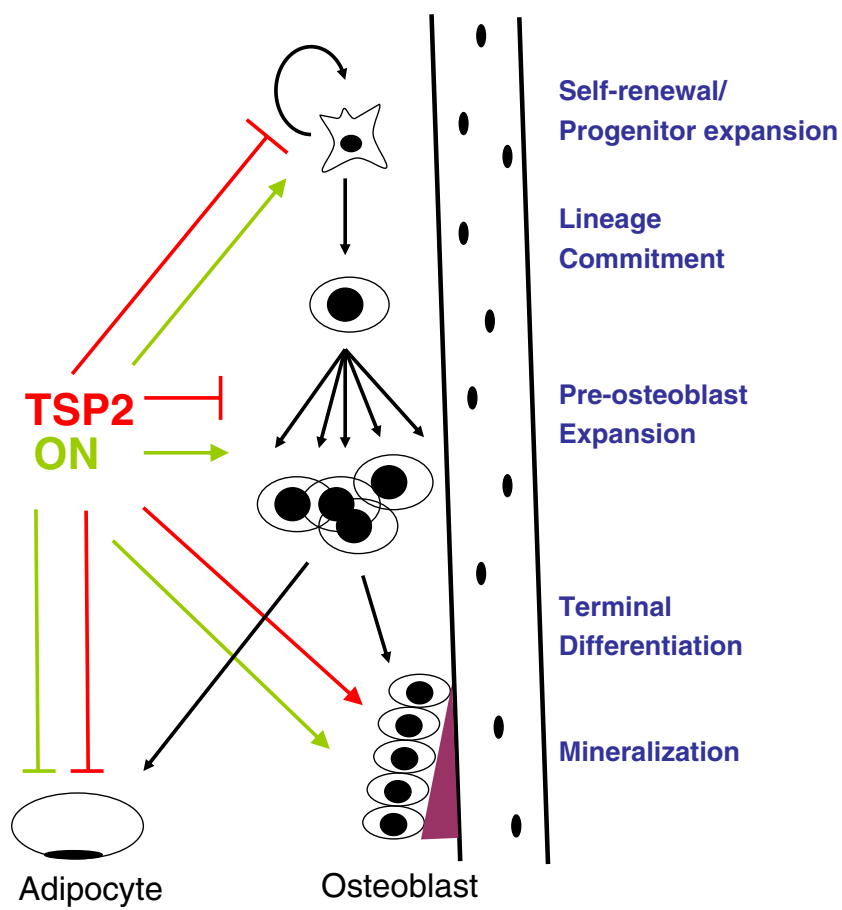

Fig. 7 Model representing the effects of TSP2 and SPARC on marrow mesenchymal progenitors. In this model it is assumed that TSP2 and SPARC are present in the marrow environment produced by mesenchymal lineage cells. While SPARC has positive effect on maintaining the mesenchymal progenitor pool and expansion of the progenitor pool, TSP2 limits this expansion. Both TSP2 and SPARC promote osteoblastogenesis/osteoblast function and decrease adipogenesis 
it is interesting to note that knockdown of TSP2 in murine osteoblasts results in the altered distribution of other ECM proteins such as osteocalcin and collagen (Alford et al. 2009).

SPARC is critical for normal bone remodeling, and it appears to modulate both osteoblasts and osteoclasts. Clearly, there is still much to be discovered about the function of SPARC in the skeleton and its mechanisms of action. Although we know that SPARC gene dosage affects the bone-anabolic response to PTH, the effect of SPARC on fracture repair and bone loss due to estrogen deprivation remains to be determined. Different SPARC expression levels in humans, mediated by genetic mechanisms, could play a role in determining the rate of fracture repair or bone loss in postmenopausal women. Furthermore, SPARC-null mice have increased osteoclast formation in response to PTH, but the molecular mechanisms underlying this effect remain largely undefined (Delany et al. 2000; Machado do Reis et al. 2008).

Osteogenic cells have been implicated as critical regulators of the hematopoietic stem cell niche, and the bone marrow from SPARC-null mice has increased $\mathrm{T}$ lymphocytes and decreased B lymphocytes (Lorenzo et al. 2008; Rempel et al. 2007). Since osteoblasts express abundant amounts of SPARC, it will be important to determine whether bone-derived SPARC affects $\mathrm{T}$ and $\mathrm{B}$ cell lineage progression or hematopoietic stem cell renewal.

The bone matrix, which includes type I collagen, noncollagen extracellular matrix components and hydroxyapatite, provides a multidimensional environment that supports the mechanical and metabolic needs of the skeleton. In addition, bone matrix serves developmental needs of cells in the bone/marrow organ, including osteoblasts, osteocytes, osteoclasts, MSC and hematopoietic cells (Balduino et al. 2005; Bi et al. 2005; Haylock and Nilsson 2005; Pizzo et al. 2005). Proteins that modulate the growth, function and survival of each cellular component have a potential to modify the balance between bone formation and bone resorption. Thrombospondins and SPARC represent primary non-collagenous constituents of bone matrix that can affect both arms of this remodeling process, thus playing a role in regulating bone structure and function.

Acknowledgments Dr. Delany is supported by NIH grant AR44877 and Dr. Hankenson is supported by NIH grants AR054714 and DE017471.

Open Access This article is distributed under the terms of the Creative Commons Attribution Noncommercial License which permits any noncommercial use, distribution, and reproduction in any medium, provided the original author(s) and source are credited.

\section{References}

Adolph KW, Liska DJ, Bornstein P (1997) Analysis of the promoter and transcription start sites of the human thrombospondin 2 gene (THBS2). Gene 193:5-11
Alford AI, Hankenson KD (2006) Matricellular proteins: extracellular modulators of bone development, remodeling, and regeneration. Bone 38:749-757

Alford AI, Terkhorn SP, Reddy AB, Hankenson KD (2009) Thrombospondin-2 regulates matrix mineralization in MC3T3-E1 pre-osteoblasts. Bone. doi:10.1016/j.bone.2009.08.058

Armstrong LC, Kyriakides TR, Bornstein P (1998) The role of thrombospondin 1 and 2 in vascular development. In: Weir EK, Archer SL, Reeves JT (eds) Fetal and neonatal pulmonary circulation. Futura, Armonk, pp 87-103

Arthur A, Zannettino A, Gronthos S (2009) The therapeutic applications of multipotential mesenchymal/stromal stem cells in skeletal tissue repair. J Cell Physiol 218:237-245

Balduino A, Hurtado SP, Frazao P, Takiya CM, Alves LM, Nasciutti LE, El-Cheikh MC, Borojevic R (2005) Bone marrow subendosteal microenvironment harbours functionally distinct haemosupportive stromal cell populations. Cell Tissue Res 319:255-266

Barker TH, Baneyx G, Cardo-Vila M, Workman GA, Weaver M, Menon PM, Dedhar S, Rempel SA, Arap W, Pasqualini R, Vogel V, Sage EH (2005) SPARC regulates extracellular matrix organization through its modulation of integrin-linked kinase activity. J Biol Chem 280:36483-36493

Bartel DP (2004) MicroRNAs: genomics, biogenesis, mechanism, and function. Cell 116:281-297

Bartel DP, Chen CZ (2004) Micromanagers of gene expression: the potentially widespread influence of metazoan microRNAs. Nat Rev Genet 5:396-400

Bein K, Ware JA, Simons M (1998) Myb-dependent regulation of thrombospondin 2 expression. Role of mRNA stability. J Biol Chem 273:21423-21429

Bi Y, Stuelten CH, Kilts T, Wadhwa S, Iozzo RV, Robey PG, Chen X-D, Young MF (2005) Extracellular matrix proteoglycans control the fate of bone marrow stromal cells. J Biol Chem 280:30481-30489

Bornstein P, Devarayalu S, Li P, Disteche CM, Framson P (1991) A second thrombospondin gene in the mouse is similar in organization to thrombospondin 1 but does not respond to serum. Proc Natl Acad Sci U S A 88:8636-8640

Boskey AL, Spevak L, Paschalis E, Doty SB, McKee MD (2002) Osteopontin deficiency increases mineral content and mineral crystallinity in mouse bone. Calcif Tissue Int 71:145-154

Boskey AL, Moore DJ, Amling M, Canalis E, Delany AM (2003) Infrared analysis of the mineral and matrix in bones of osteonectin-null mice and their wildtype controls. J Bone Miner Res 18:1005-1011

Canalis E, Giustina A, Bilezikian JP (2007) Mechanisms of anabolic therapies for osteoporosis. N Engl J Med 357:905-916

Carron JA, Bowler WB, Wagstaff SC, Gallagher JA (1999) Expression of members of the thrombospondin family by human skeletal tissues and cultured cells. Biochem Biophys Res Commun 263:389-391

Chamboredon S, Briggs J, Vial E, Hurault J, Galvagni F, Oliviero S, Bos T, Castellazzi M (2003) v-Jun downregulates the SPARC target gene by binding to the proximal promoter indirectly through Sp1/3. Oncogene 22:4047-4061

Crawford SE, Stellmach V, Murphy-Ullrich JE, Ribeiro SM, Lawler J, Hynes RO, Boivin GP, Bouck N (1998) Thrombospondin-1 is a major activator of TGF-beta1 in vivo. Cell 93:1159-1170

Delany AM, Canalis E (1998) Basic fibroblast growth factor destabilizes osteonectin mRNA in osteoblasts. Am J Physiol 274:C734-C740

Delany AM, Amling M, Priemel M, Howe C, Baron R, Canalis E (2000) Osteopenia and decreased bone formation in osteonectindeficient mice. J Clin Invest 105:915-923

Delany AM, Kalajzic I, Bradshaw AD, Sage EH, Canalis E (2003) Osteonectin-null mutation compromises osteoblast formation, maturation, and survival. Endocrinology 144:2588-2596 
Delany AM, McMahon DJ, Powell JS, Greenberg DA, Kurland ES (2008) Osteonectin/SPARC polymorphisms in Caucasian men with idiopathic osteoporosis. Osteoporos Int 19:969-978

Dieudonn KJM, Xu T, Sommer B, Derubeis AR, Kuznetsov SA, Kim IS, Gehron RP, Young MF (1999) Differential display of human marrow stromal cells reveals unique mRNA expression patterns in response to dexamethasone. J Cell Biochem 76:231-243

Dominguez P, Ibaraki K, Gehron Robey P, Hefferan TE, Termine JD, Young MF (1991) Expression of the osteonectin gene potentially controlled by multiple cis- and trans-acting factors in cultured bone cells. J Bone Miner Res 10:1127-1136

Fedarko NS, Moerike M, Brenner R, Robey PG, Vetter U (1992) Extracellular matrix formation by osteoblasts from patients with osteogenesis imperfecta. J Bone Miner Res 7:921-930

Fisher LW, Robey PG, Tuross N, Otsuka AS, Tepen DA, Esch FS, Shimasaki S, Termine JD (1987) The Mr 24, 000 phosphoprotein from developing bone is the NH2-terminal propeptide of the alpha 1 chain of type I collagen. J Biol Chem 262:13457-13463

Frank O, Heim M, Jakob M, Barbero A, Schafer D, Bendik I, Dick W, Heberer M, Martin I (2002) Real-time quantitative RT-PCR analysis of human bone marrow stromal cells during osteogenic differentiation in vitro. J Cell Biochem 85:737-746

Gross TS, Srinivasan S, Liu CC, Clemens TL, Bain SD (2002) Noninvasive loading of the murine tibia: an in vivo model for the study of mechanotransduction. J Bone Miner Res 17:493-501

Hafner M, Zimmermann K, Pottgiesser J, Krieg T, Nischt R (1994) A purine-rich sequence in the human BM-40 gene promoter region is a prerequisite for maximal transcription. Matrix Biol 14:733-741

Hankenson KD, Bornstein P (2002) The secreted protein thrombospondin 2 is an autocrine inhibitor of marrow stromal cell proliferation. J Bone Miner Res 17:415-425

Hankenson KD, Bain SD, Kyriakides TR, Smith EA, Goldstein SA, Bornstein P (2000) Increased marrow-derived osteoprogenitor cells and endosteal bone formation in mice lacking thrombospondin 2. J Bone Miner Res 15:851-862

Hankenson KD, James IE, Apone S, Stroup GB, Blake SM, Liang X, Lark MW, Bornstein P (2005a) Increased osteoblastogenesis and decreased bone resorption protect against ovariectomy-induced bone loss in thrombospondin-2-null mice. Matrix Biol 24:362-370

Hankenson KD, Hormuzdi SG, Meganck JA, Bornstein P (2005b) Mice with a disruption of the thrombospondin 3 gene differ in geometric and biomechanical properties of bone and have accelerated development of the femoral head. Mol Cell Biol 25:5599-5606

Hankenson KD, Ausk BJ, Bain SD, Bornstein P, Gross TS, Srinivasan S (2006) Mice lacking thrombospondin 2 show an atypical pattern of endocortical and periosteal bone formation in response to mechanical loading. Bone 38:310-316

Haylock DN, Nilsson SK (2005) Stem cell regulation by the hematopoietic stem cell niche. Cell Cycle 4:1353-1355

Hilton MJ, Tu X, Wu X, Bai S, Zhao H, Kobayashi T, Kronenberg HM, Teitelbaum SL, Ross FP, Kopan R, Long F (2008) Notch signaling maintains bone marrow mesenchymal progenitors by suppressing osteoblast differentiation. Nat Med 14:306-314

Iruela-Arispe ML, Liska DJ, Sage EH, Bornstein P (1993) Differential expression of thrombospondin 1,2, and 3 during murine development. Dev Dyn 197:40-56

Jing Q, Huang S, Guth S, Zarubin T, Motoyama A, Chen J, Di Padova F, Lin SC, Gram H, Han J (2005) Involvement of microRNA in AU-rich element-mediated mRNA instability. Cell 120:623-634

Kapinas K, Kessler CB, Delany AM (2009) 2009 miR-29 suppression of osteonectin in osteoblasts: regulation during differentiation and by canonical wnt signaling. J Cell Biochem 108:216224

Kessler CB, Delany AM (2007) Increased Notch 1 expression and attenuated stimulatory $\mathrm{G}$ protein coupling to adenylyl cyclase in osteonectin-null osteoblasts. Endocrinology 148:1666-1674
Krady MM, Zeng J, Yu J, Maclauchlan S, Skokos EA, Tian W, Bornstein P, Sessa WC, Kyriakides TR (2008) Thrombospondin2 modulates extracellular matrix remodeling during physiological angiogenesis. Am J Pathol 173:879-891

Kuwata F, Yao KL, Sodek J, Ives S, Pulleyblank D (1985) Identification of pre-osteonectin produced by cell-free translation of fetal porcine calvarial mRNA. J Biol Chem 260:6993-6998

Kveiborg M, Sabatakos G, Chiusaroli R, Wu M, Philbrick WM, Horne WC, Baron R (2004) DeltaFosB induces osteosclerosis and decreases adipogenesis by two independent cell-autonomous mechanisms. Mol Cell Biol 24:2820-2830

Kyriakides TR, Zhu YH, Smith LT, Bain SD, Yang Z, Lin MT, Danielson KG, Iozzo RV, LaMarca M, McKinney CE, Ginns EI, Bornstein P (1998a) Mice that lack thrombospondin 2 display connective tissue abnormalities that are associated with disordered collagen fibrillogenesis, an increased vascular density, and a bleeding diathesis. J Cell Biol 140:419-430

Kyriakides TR, Zhu YH, Tam JWY, Yang Z, Bornstein P (1998b) Accelerated wound healing in mice with a disruption of the thrombospondin 2 gene. Mol Biol Cell 9:342

Kyriakides TR, Zhu YH, Yang Z, Bornstein P (1998c) The distribution of the matricellular protein, thrombospondin 2 , in tissues of embryonic and adult mice. J Histochem Cytochem 46:1007-1015

Kyriakides TR, Tam JW, Bornstein P (1999) Accelerated wound healing in mice with a disruption of the thrombospondin 2 gene. J Invest Dermatol 113:782-787

Kyriakides TR, Rojnuckarin P, Reidy MA, Hankenson KD, Papayannopoulou T, Kaushansky K, Bornstein P (2003) Megakaryocytes require thrombospondin-2 for normal platelet formation and function. Blood 101:3915-3923

Laherty CD, O'Rourke K, Wolf FW, Katz R, Seldin MF, Dixit VM (1992) Characterization of mouse thrombospondin 2 sequence and expression during cell growth and development. J Biol Chem $267: 3274-3281$

Lawler J (2000) The functions of thrombospondin-1 and-2. Curr Opin Cell Biol 12:634-640

Lee SK, Lorenzo JA (1999) Parathyroid hormone stimulates TRANCE and inhibits osteoprotegerin messenger ribonucleic acid expression in murine bone marrow cultures: correlation with osteoclast-like cell formation. Endocrinology 140:3552-3561

Lewis BP, Shih IH, Jones-Rhoades MW, Bartel DP, Burge CB (2003) Prediction of mammalian microRNA targets. Cell 115:787-798

Li K, Cai R, Dai BB, Zhang XQ, Wang HJ, Ge SF, Xu WR, Lu J (2007) SATB1 regulates SPARC expression in K562 cell line through binding to a specific sequence in the third intron. Biochem Biophys Res Commun 356:6-12

Lian JB, Stein GS (1992) Concepts of osteoblast growth and differentiation: basis for modulation of bone cell development and tissue formation. Crit Rev Oral Biol Med 3:269-305

Ling Y, Rios HF, Myers ER, Lu Y, Feng JQ, Boskey AL (2005) DMP1 depletion decreases bone mineralization in vivo: an FTIR imaging analysis. J Bone Miner Res 20:2169-2177

Lorenzo J, Horowitz M, Choi Y (2008) Osteoimmunology: interactions of the bone and immune system. Endocr Rev 29:403-440

Machado do Reis L, Kessler CB, Adams DJ, Lorenzo J, Jorgetti V, Delany AM (2008) Accentuated osteoclastic response to parathyroid hormone undermines bone mass acquisition in osteonectin-null mice. Bone 43:264-273

Malaval L, Liu F, Roche P, Aubin JE (1999) Kinetics of osteoprogenitor proliferation and osteoblast differentiation in vitro. J Cell Biochem 74:616-627

Mansergh FC, Wells T, Elford C, Evans SL, Perry MJ, Evans MJ, Evans BA (2007) Osteopenia in Sparc (osteonectin)-deficient mice: characterization of phenotypic determinants of femoral strength and changes in gene expression. Physiol Genomics 32:64-73 
Meng H, Zhang X, Hankenson KD, Wang MM (2009) Thrombospondin 2 potentiates notch3/Jagged 1 signaling. J Biol Chem 284:7866-7844

Muriel MP, Bonaventure J, Stanescu R, Maroteaux P, Guenet JL, Stanescu V (1991) Morphological and biochemical studies of a mouse mutant (fro/fro) with bone fragility. Bone 12:241-248

Nadiarnykh O, Plotnikov S, Mohler WA, Kalajzic I, Redford-Badwal D, Campagnola PJ (2007) Second harmonic generation imaging microscopy studies of osteogenesis imperfecta. J Biomed Opt 12:051805

Ng KW, Manji SS, Young MF, Findlay DM (1989) Opposing influences of glucocorticoid and retinoic acid on transcriptional control in preosteoblasts. Mol Endocrinol 3:2079-2085

Nishiwaki T, Yamaguchi T, Zhao C, Amano H, Hankenson KD, Bornstein P, Toyama Y, Matsuo K (2006) Reduced expression of thrombospondins and craniofacial dysmorphism in mice overexpressing Fra1. J Bone Miner Res 21:596-604

Oritani K, Kincade PW (1996) Identification of stromal cell products that interact with pre-B cells. J Cell Biol 134:771-782

Pizzo AM, Kokini K, Vaughn LC, Waisner BZ, Voytik-Harbin SL (2005) Extracellular matrix (ECM) microstructural composition regulates local cell-ECM biomechanics and fundamental fibroblast behavior: a multidimensional perspective. J Appl Physiol 98:1909-1921

Posey KL, Hankenson K, Veerisetty AC, Bornstein P, Lawler J, Hecht JT (2008) Skeletal abnormalities in mice lacking extracellular matrix proteins, thrombospondin-1, thrombospondin-3, thrombospondin-5, and type IX collagen. Am J Pathol 172:1664-1674

Rempel SA, Hawley RC, Gutiérrez JA, Mouzon E, Bobbitt KR, Lemke N, Schultz CR, Schultz LR, Golembieski W, Koblinski J, VanOsdol S, Miller CG (2007) Splenic and immune alterations of the Sparc-null mouse accompany a lack of immune response. Genes Immun 8:262-274

Robey PG, Boskey AL, Lian JB, Goldring SR (2006) Chapter 3. Extracellular matrix and biomineralization of bone. Primer 6:12-19

Sabatakos G, Rowe GC, Kveiborg M, Wu M, Neff L, Chiusaroli R, Philbrick WM, Baron R (2008) Doubly truncated FosB isoform (Delta2DeltaFosB) induces osteosclerosis in transgenic mice and modulates expression and phosphorylation of Smads in osteoblasts independent of intrinsic AP-1 activity. J Bone Miner Res 23:584-595
Schroen B, Heymans S, Sharma U, Blankesteijn WM, Pokharel S, Cleutjens JP, Porter JG, Evelo CT, Duisters R, van Leeuwen RE, Janssen BJ, Debets JJ, Smits JF, Daemen MJ, Crijns HJ, Bornstein P, Pinto YM (2004) Thrombospondin-2 is essential for myocardial matrix integrity: increased expression identifies failure-prone cardiac hypertrophy. Circ Res 95:515-522

Seeman E, Delmas PD (2006) Bone quality-the material and structural basis of bone strength and fragility. N Engl J Med 354:2250-2261

Shitaye H, Frohm ML, Miller JD, Hankenson KD (2005) Regulation of Thrombospondin-2 expression during marrow stromal cell differentiation. In: American Society of Bone and Mineral Research Annual Meeting, Nashville TN

Shitaye H, Torre C, Hankenson KD (2009) Thrombospondin-2 modulates notch signaling in bone marrow stromal cells. In: American Society of Bone and Mineral Research Annual Meeting, Denver CO. M085

Stein GS, Lian JB (1993) Molecular mechanisms mediating proliferation/differentiation interrelationships during progressive development of the osteoblast phenotype. Endocr Rev 14:424-442

Streit M, Riccardi L, Velasco P, Brown LF, Hawighorst T, Bornstein P, Detmar M (1999) Thrombospondin-2: a potent endogenous inhibitor of tumor growth and angiogenesis. Proc Natl Acad Sci U S A 96:14888-14893

Taylor DK, Meganck JA, Terkhorn S, Rajani R, Naik A, O'Keefe RJ, Goldstein SA, Hankenson KD (2009) Thrombospondin-2 influences the proportion of cartilage and bone during fracture healing. J Bone Miner Res 24:1043-1054

Termine JD, Robey PG, Fisher LW, Shimokawa H, Drum MA, Conn KM, Hawkins GR, Cruz JB, Thompson KG (1984) Osteonectin, bone proteoglycan, and phosphophoryn defects in a form of bovine osteogenesis imperfecta. Proc Natl Acad Sci USA 81:2213-2217

Wrana JL, Maeno M, Hawrylyshyn B, Yao KL, Domenicucci C, Sodek J (1988) Differential effects of transforming growth factorbeta on the synthesis of extracellular matrix proteins by normal fetal rat calvarial bone cell populations. J Cell Biol 106:915-924

Xiao Z, Camalier CE, Nagashima K, Chan KC, Lucas DA, de la Cruz MJ, Gignac M, Lockett S, Issaq HJ, Veenstra TD, Conrads TP, Beck GR Jr (2007) Analysis of the extracellular matrix vesicle proteome in mineralizing osteoblasts. J Cell Physiol 210:325-335

Yang E, Kang HJ, Koh KH, Rhee H, Kim NK, Kim H (2007) Frequent inactivation of SPARC by promoter hypermethylation in colon cancers. Int J Cancer 121:567-575 